\title{
Prevention of invasive fungal infections in immunocompromised patients: the role of delayed-release posaconazole
}

This article was published in the following Dove Press journal:

Infection and Drug Resistance

9 September 2015

Number of times this article has been viewed

\author{
Ahmet Soysal \\ Division of Pediatric Infectious \\ Diseases, Department of Pediatrics, \\ Faculty of Medicine, Marmara \\ University, Istanbul, Turkey
}

Correspondence: Ahmet Soysal TC Sağlık Bakanlığı-Marmara Üniversitesi Pendik Eğitim ve Araștırma Hastanesi, Çocuk Enfeksiyon Hastalıkları Bilim Dalı, Fevzi Çakmak Mah, Mimar Sinan Caddesi, Üstkaynarca, Pendik, Istanbul, Turkey Tel +90216 6254526

Email asoysal@marmara.edu.tr

\begin{abstract}
Posaconazole is a triazole antifungal agent that has broad-spectrum activity against many yeasts and filamentous fungi, including Candida species, Cryptococcus neoformans, Aspergillus species, and Zygomycetes. This drug has been approved for the prevention of invasive fungal infections in patients with neutropenia and for the treatment of invasive fungal infections in hematopoietic stem cell transplant recipients with graft-versus-host disease. Studies on the clinical efficacy, safety, tolerability, and cost-effectiveness of posaconazole therapy were performed using the oral suspension form of the drug. Pharmacokinetic studies have found that the oral suspension form of posaconazole has problemeatic bioavailability: its absorption is affected by concomitant medication and food. This article discusses the pharmacokinetic properties of the newly developed posaconazole delayed-release tablet formulation and reviews the efficacy, safety, and cost-effectiveness of both the oral suspension and the new tablet formulation. In conclusion, the posaconazole tablet formulation has better systemic bioavailability, thereby enabling once-daily administration and better absorption in the presence of concomitant medication and food. However, well-designed clinical studies are needed to evaluate the use of the tablet formulation in real-life settings.
\end{abstract}

Keywords: posaconazole delayed-release tablet, prophylaxis, invasive fungal infections

\section{Introduction}

Invasive fungal infections (IFIs) are a common cause of morbidity and mortality in immunocompromised patients. The incidence of IFIs in immunocompromised patients depends on the following factors: the age of patients; underlying diseases, such as hematologic malignancies, solid organ cancers, hematopoietic stem cell transplantation (HSCT), solid organ transplantation, AIDS, primary immunodeficiencies, and secondary immunodeficiencies; chemotherapy regimens; and systemic antifungal prophylaxis administration. The incidence of IFIs has ranged from $2 \%-49 \%$ in adult patients. ${ }^{1}$ In pediatric age groups, the incidence of IFIs is approximately $10 \%$ or higher in populations of patients with acute myeloid leukemia (AML) or recurrent acute leukemia (RAL) and in patients who undergo allogeneic HSCT. ${ }^{2}$

The incidence of IFIs in patients with acute lymphatic leukemia are more variable, depending on the protocol and the cumulative presence of risk factors. The incidence of IFIs is considerably lower $(<5 \%)$ in patients with non-Hodgkin lymphoma and in patients who undergo autologous HSCT, and IFIs are sporadic in patients with pediatric solid tumors, brain tumors, and Hodgkin's lymphoma. ${ }^{2}$ Moreover, pediatric patients with primary immunodeficiencies have an increased incidence of superficial fungal 
infections and IFIs. Inborn errors of the phagocyte NADPH oxidase complex (chronic granulomatous disease), severe congenital neutropenia, and leukocyte adhesion deficiency type I confer a predisposition to invasive aspergillosis and candidiasis. More rarely, inborn errors of IFN- $\gamma$ immunity predispose individuals to endemic mycoses. Inborn errors of IL-17 immunity have recently been demonstrated to predispose individuals to chronic mucocutaneous candidiasis, whereas inborn errors of CARD9 immunity predispose individuals to deep dermatophytosis and invasive candidiasis. Chronic mucocutaneous candidiasis, invasive candidiasis, invasive aspergillosis, deep dermatophytosis, pneumocystosis, and endemic mycoses have all been observed in patients with primary immunodeficiencies. ${ }^{3}$ The overall case-fatality rates of IFIs have ranged from $20 \%-70 \%$, with the poorest outcomes in patients with disseminated disease, central nervous system involvement, or persistent neutropenia. ${ }^{2}$

Both yeasts and molds cause serious IFIs in immunocompromised patients. Candida is the most common yeast pathogen, accounting for most invasive yeast infections. ${ }^{4}$ On the other hand, Aspergillus is the most common mold pathogen in immunocompromised patients. ${ }^{5}$ Other fungal pathogens, including Trichosporium spp., Fusarium spp., Scedosporium spp., and Zygomycetes have been described in immunocompromised patients. Cho and Choi reported a high rate of fungal infections in autopsy findings from patients who died after prolonged neutropenic fever between 1966 and 1975. More than half of these patients had Candida infections. These findings supported the use of antifungal prophylaxis in immunocompromised patients. ${ }^{6}$ In a doubleblinded, randomized, multicenter trial, Goodman et al demonstrated that fluconazole prophylaxis reduced the incidence of both systemic and superficial fungal infections in severely immunocompromised patients who underwent bone marrow transplantation. ${ }^{7}$

In this review, we summarize the use of posaconazole, especially the delayed-release tablet formulation, for the prevention of IFIs in immunocompromised patients.

\section{Posaconazole}

Posaconazole is a recently developed second-generation azole antifungal drug. This drug is derived from itraconazole by replacing the chlorine substituents in the phenyl ring with fluorine and by hydroxylating the triazolone side chain, which improves its potency and spectrum of activity. Posaconazole is designated chemically as 4-[4-[4-[4-[[(3R,5R)-5-(2,4-difluorophenyl) tetrahydro5-(1H-1,2,4-triazol-1-ylmethyl)-3-furanyl]methoxy]
phenyl]-1-piperazinyl]phenyl]-2-[(1S,2S)-1-ethyl-2hydroxypropyl]-2,4-dihydro-3 $\mathrm{H}$-1,2,4-triazol-3-one. The chemical formula for posaconazole is $\mathrm{C}_{37} \mathrm{H}_{42} \mathrm{~F}_{2} \mathrm{~N}_{8} \mathrm{O}_{4}$, and its molecular weight is 700.8 . Figure 1 shows the structural formula of posaconazole. ${ }^{8}$

\section{Mechanisms of action}

Similar to all azole antifungal agents, posaconazole inhibits cytochrome P450 (CYP450)-dependent lanosterol 14 alpha-demethylase (CYP51), which is an enzyme required for ergosterol synthesis and a major sterol component in the cell membrane of fungal cells. ${ }^{9}$ The inhibition of ergosterol synthesis by posaconazole leads to a depletion of ergosterol. The shortage of ergosterol weakens the stability of the fungal cell membrane, the transport of nutrients, and the synthesis of chitin. ${ }^{8}$ Furthermore, the inhibition of ergosterol synthesis causes the accumulation of toxic methylated ergosterol precursors, which leads to damage of the fungal cell membrane and increased permeability and inhibition of fungal cell growth. ${ }^{10}$ The mechanisms of resistance to azole antifungals arises either from mutations in the ERG11 gene encoding the target enzyme CYP51 or from the overexpression of efflux pumps. ${ }^{8}$

\section{Spectrum of activity}

Posaconazole is active against all fungi with ergosterol in their cytoplasmic membrane. This drug exhibits organismdependent fungicidal activity. Posaconazole has fungistatic activity against most Candida spp. and fungicidal activity against Aspergillus spp. and Mucormycetes. ${ }^{11}$ In contrast to fluconazole, itraconazole, and voriconazole, the breakpoints of susceptibility/resistance to posaconazole have not yet been sufficiently established. However, the epidemiological cut-off (ECOFF) values have been described using European Committee on Susceptibility Testing (EUCAST) methodology. ${ }^{12}$ The ECOFF for itraconazole resistance in A. fumigatus, A. flavus, $A$. nidulans, and $A$. terreus is $>2 \mathrm{mg} / \mathrm{L}$. The ECOFFs for posaconazole and voriconazole resistance in A. fumigatus are $>0.25 \mathrm{mg} / \mathrm{L}$ and $>2 \mathrm{mg} / \mathrm{L}$, respectively. The Clinical and

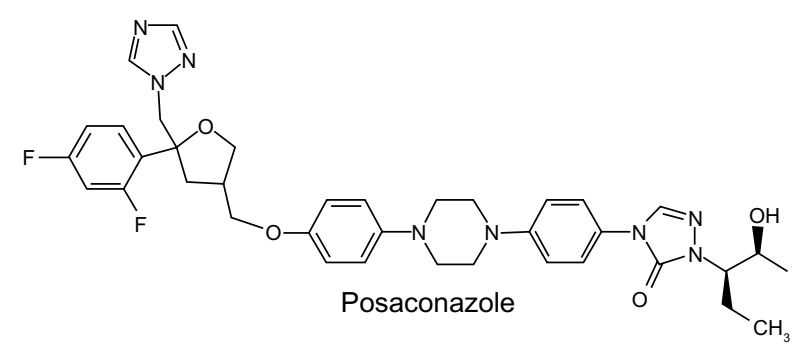

Figure I The structural formula of posaconazole. 
Laboratory Standards Institute breakpoint for itraconazole and voriconazole resistance in A. fumigatus, A. flavus, and A. terreus is $>1 \mathrm{mg} / \mathrm{L}$, and the breakpoint against $A$. niger and $A$. versicolor is $>2 \mathrm{mg} / \mathrm{L}$. In addition, the breakpoint for posaconazole resistance in A. fumigatus, A. flavus, and A. terreus is $>0.5 \mathrm{mg} / \mathrm{L} .{ }^{13}$ Moreover, the EUCAST minimum inhibitory concentration (MIC) breakpoints for posaconazole susceptibility and resistance in C. albicans, C. tropicalis, and C. parapsilosis are $\leq 0.06 \mathrm{mg} / \mathrm{L}$ and $>0.06 \mathrm{mg} / \mathrm{L}$, respectively. ${ }^{12}$ However, the clinical breakpoints have not been established yet for other species of Candida. A novel study investigated 1,717 clinical isolates from patients with IFIs at 72 laboratories in North America, Europe, Latin America, and the Asia-Pacific region as part of the 2012 SENTRY Antimicrobial Surveillance Program. ${ }^{14}$ In this study posaconazole resistance for Candida species were found to be vary from $0.4 \%$ in C. parapsilosis strains to $5.6 \%$ in C. krusei strains. ${ }^{14}$ Posaconazole has encouraging activity against Zygomycetes. Posaconazole and itraconazole are the only available azoles that demonstrate activity against most Zygomycetes. However, itraconazole was significantly less active than posaconazole against all Zygomycetes species. ${ }^{15} \mathrm{~A}$ comparative study found that posaconazole exhibited lower MICs against Zygomycetes isolates than voriconazole and itraconazole. However, the antifungal activity of posaconazole was lower than that of amphotericin B. Sun et al compared the in vitro activities of posaconazole, itraconazole, voriconazole, amphotericin B, and fluconazole against 37 clinical isolates of Zygomycetes. ${ }^{16}$ They found that the MICs (means) of posaconazole were approximately 1.6-fold, 33-fold, and 47-fold lower than those of itraconazole, voriconazole, and fluconazole, respectively. However, amphotericin B had the lowest MICs against all Zygomycetes isolates. ${ }^{16}$ Zygomycetes species differ in their susceptibility to posaconazole: MICs have ranged from 0.25 to $8 \mu \mathrm{g} / \mathrm{mL}$ for Rhizopus species, from 0.125 to $8 \mu \mathrm{g} / \mathrm{mL}$ for $M u c o r$ species, from 0.03 to $0.25 \mu \mathrm{g} /$ $\mathrm{mL}$ for $A$. corymbifera, and from 0.03 to $1 \mu \mathrm{g} / \mathrm{mL}$ for $C u n$ ninghamella spp. ${ }^{16}$ The activity of posaconazole against the clinical isolates of Zygomycetes was lower than that of amphotericin B but higher than that of voriconazole, fluconazole, and itraconazole. ${ }^{16}$ Therefore, posaconazole exhibits potent activity against a large spectrum of fungi.

\section{Pharmacokinetics and metabolism}

Since 2006, posaconazole has been approved for use in the United States as an oral suspension. The Food and Drug Administration (FDA) approved a new delayed-release tablet formulation of posaconazole in November 2013.
Recently, in March 2014, the FDA approved an intravenous formulation of posaconazole. ${ }^{17}$ Posaconazole is extensively distributed throughout the body, with good extravascular tissue penetration (volume of distribution 5-25 L/kg). Posaconazole is highly protein-bound ( $>98 \%$ ), predominantly to albumin. Posaconazole has been primarily found as the parent compound in plasma. This drug undergoes limited hepatic metabolism. Of the circulating metabolites of posaconazole, the majority are glucuronide conjugates formed via UDP-glucuronidation. Posaconazole does not have any major oxidative metabolites of the CYP450 system. ${ }^{1}$ The mean half-life of posaconazole is 35 hours (20-66 hours), and its total body clearance is $32 \mathrm{~L} /$ hour. $^{18}$ The elimination of posaconazole occurs predominantly through fecal excretion (77\%), with the major component eliminated as the parent drug $(66 \%)$ and to a lesser extent via renal clearance (14\%). ${ }^{19,20}$ The pharmacokinetics of posaconazole in patients with hepatic dysfunction have not been sufficiently evaluated; however, dose adjustments are currently not recommended in patients with hepatic impairment, but posaconazole must be used with caution in patients with hepatic dysfunction. ${ }^{18}$ Posaconazole use in patients with renal dysfunction has been evaluated in a limited number of studies. Courtney et al evaluated the pharmacokinetics and safety of posaconazole in healthy subjects and in patients with mild (creatinine clearance [CR] 50-80 mL/min), moderate (CR 20-49 mL/min), and severe chronic renal disease ( $\mathrm{CR}<20 \mathrm{~mL} / \mathrm{min}$; receiving outpatient hemodialysis). They found no correlation between posaconazole pharmacokinetics and mild-to-moderate renal disease. In addition, they found that the difference in the pre-dialyzed and postdialyzed posaconazole concentrations was approximately $3 \%$, which suggests that posaconazole was not removed by hemodialysis. The results of this study indicate that dosage adjustments for patients with varying degrees of renal disease are not required and that the drug was not removed by hemodialysis. ${ }^{21}$ These data demonstrate that posaconazole can be administered without dose adjustments, and supplemental doses are not needed after hemodialysis. However, sufficient data on the pharmacokinetics of posaconazole are not available in children. Krishna et al investigated the pharmacokinetic parameters, adverse events, and treatment outcomes of posaconazole as salvage therapy for IFIs in children younger than 18 years of age. ${ }^{22}$ In this small study, the researchers found that posaconazole concentrations in plasma were similar for juvenile and adult patients, which suggests that the clinical outcomes would be similar in adults and children with refractory IFIs. ${ }^{22}$ 


\section{Posaconazole oral suspension}

The oral suspension of posaconazole is a white powder that is insoluble in water. Posaconazole (Noxafil) oral suspension is a white, cherry-flavored immediate-release suspension that contains $40 \mathrm{mg}$ of posaconazole per $\mathrm{mL}$. The pharmacokinetic properties of posaconazole have been studied in healthy adult volunteers. ${ }^{19,23}$ Courtney et al investigated the pharmacokinetics, safety, and tolerability of posaconazole in 103 healthy adults using a rising single-dose or rising multiple-dose schedule. In this study, the subjects either received single doses of posaconazole oral tablets (50-1,200 mg), rising multiple-dose posaconazole oral tablets (50-400 mg), or placebo. They reported that in the rising single-dose study, the levels of posaconazole in plasma increased proportionally with doses of $50-800 \mathrm{mg}$, and saturation of absorption occurred above $800 \mathrm{mg}$. Additionally, dose proportionality was observed in the rising multiple-dose study. In both studies, the authors found that the volume of distribution of posaconazole was large (range: $343-1,341$ L), and the terminal-phase half-life of posaconazole was long (range: 25-31 hours). In those studies, posaconazole was well tolerated at all dose levels, and the adverse events were not dose-dependent. Following the administration of single- and twice-daily rising doses, the level of posaconazole exposure increased in a dose-proportional manner. ${ }^{23}$ Krieter et al investigated the pharmacokinetics of posaconazole in eight healthy male subjects who received a single $399 \mathrm{mg}$ oral dose of posaconazole after consuming a high-fat breakfast. They found that posaconazole was orally bioavailable, and the median maximum concentration in plasma was achieved by 10 hours following dosing. Thereafter, posaconazole was slowly eliminated, with a mean half-life of 20 hours. ${ }^{19}$ The steady-state concentrations of posaconazole were reached 7-10 days after the initiation of treatment. ${ }^{19,23}$ The consumption of food greatly affects posaconazole absorption similar to itraconazole. The absorption of the oral suspension is approximately three times higher when administered with a non-fat meal and approximately four times higher when administered with a high-fat meal. ${ }^{19,23}$ Therefore, to attain adequate plasma concentrations, recommendations suggest taking posaconazole with food or a nutritional supplement. The posaconazole oral suspension exhibits a greater degree of unpredictable bioavailability outside of ideal study conditions and in patients other than healthy adults. Interpatient variability of approximately $68 \%$ has been observed in neutropenic stem cell transplant recipients. ${ }^{24}$ Several studies have investigated the relationship between gastric motility, drug absorption, and posaconazole plasma concentrations.
Diarrhea, mucositis, and graft-versus-host disease (GVHD) affect the absorption of posaconazole suspension. Moreover, many studies have demonstrated that gastric acid suppression therapy results in subtherapeutic posaconazole concentrations. ${ }^{25-27}$

\section{Posaconazole oral delayed-release tablet}

The posaconazole delayed-release tablet is yellow, coated, and oblong, and it contains $100 \mathrm{mg}$ of posaconazole. Each delayed-release tablet contains the following inactive ingredients: hypromellose acetate succinate, microcrystalline cellulose, hydroxypropyl cellulose, silicon dioxide, croscarmellose sodium, magnesium stearate, and Opadry ${ }^{\circledR}$ II Yellow (consisting of the following ingredients: polyvinyl alcohol partially hydrolyzed, macrogol/PEG 3350, titanium dioxide, talc, and iron oxide yellow) ${ }^{17}$ Posaconazole delayed-release tablets must be swallowed whole and cannot be divided, crushed, or chewed. The delayed-release tablet and oral suspension may not be used interchangeably due to differences in the dosing of each formulation. The first study to evaluate the pharmacokinetics of the delayed-release tablet formulation was a single-dose crossover study in 16 healthy adults under fasted and fed conditions. This study was aimed at assessing the safety and tolerability of the drug. ${ }^{28}$ In this study, the pharmacokinetics of $100 \mathrm{mg}$ of posaconazole oral suspension, $100 \mathrm{mg}$ of a posaconazole two-tablet formulation, and $100 \mathrm{mg}$ of a posaconazole capsule formulation were assessed. Under fasted conditions, the posaconazole exposures (area under the curve [AUC]) for the first tablet and second capsule formulations against oral suspension formulation were similar (mean AUC from zero to infinity $\left[\mathrm{AUC}_{0-\infty}\right]: 11,700 / 11,300 \mathrm{ng} \cdot \mathrm{h} / \mathrm{mL}$ versus $11,000 \mathrm{ng} \cdot \mathrm{h} / \mathrm{mL}$ ) and were substantially higher than the exposure for the oral suspension (mean $\mathrm{AUC}_{0-\infty}: 3,420 \mathrm{ng} \cdot \mathrm{h} / \mathrm{mL}$ ). Moreover, in the fed subjects, the first tablets and second capsule against oral suspension form had similar mean $\mathrm{AUC}_{0-\infty}$ values $(11,900 / 12,400 \mathrm{ng} \cdot \mathrm{h} / \mathrm{mL}$ versus $12,300 \mathrm{ng} \cdot \mathrm{h} / \mathrm{mL})$ and slightly higher mean $\mathrm{AUC}_{0-\infty}$ values $(8,750 \mathrm{ng} \cdot \mathrm{h} / \mathrm{mL})$ than the oral suspension. The researchers demonstrated that the median times to the maximum concentration of the drug in plasma ranged from 4 to 5 hours (fasted conditions) and 6 to 8 hours (fed conditions), and the mean half-life values were similar for all the formulations under fed and fasted conditions (23.1-29.2 hours). Consistent with previous data on the posaconazole oral suspension, exposure for the oral suspension increased 2.5- to threefold when given with a high-fat meal. Conversely, the exposures for the tablets and capsule were not markedly affected by food. This study demonstrated 
that all formulations of posaconazole at $100 \mathrm{mg}$ were safe and well tolerated, and the tablet and capsule formulations were not affected by food. These same researchers performed a second Phase I single-center, randomized, placebo-controlled trial to investigate rising single and multiple doses of posaconazole in healthy subjects of 18-65 years of age. The subjects received posaconazole oral tablets $(100 \mathrm{mg})$ as 200 $\mathrm{mg}$ once daily (QD), $200 \mathrm{mg}$ twice daily, or $400 \mathrm{mg}$ QD. ${ }^{29}$ After the single or multiple oral dose administration of posaconazole tablets (200 and $400 \mathrm{mg}$ ), exposure increased in a dose-related manner, and peak posaconazole concentrations were achieved at a median $\mathrm{T}(\max )$ of 4-5 hours. The mean half-life of the 200 and $400 \mathrm{mg}$ posaconazole doses were similar (25 and 26 hours, respectively). The accumulation ratio for multiple doses over 8 days was approximately 3 for the 200 and $400 \mathrm{mg}$ QD dosages and approximately 5 for the $200 \mathrm{mg}$ twice-daily dosage. The posaconazole tablet formulation attained mean average concentration $\left(\mathrm{C}_{\text {avg }}\right)$ values $>1,300 \mathrm{ng} / \mathrm{mL}$ at the lowest dose (200 mg QD), and these values were above the average concentration values that are associated with efficacy in patients with IFIs. This study concluded that the posaconazole oral tablet was safe and well tolerated and that the QD dosing regimens were appropriate for fungal infections; however, mild, transient elevations in liver function were reported in several patients.

Thereafter, a Phase Ib global (nine centers in four different countries), open-labeled, uncontrolled, dose-escalation, prospective pharmacokinetics and safety trial was conducted in adults with AML or myelodysplastic syndrome (MDS) who were undergoing remission-induction chemotherapy with prolonged neutropenia for at least 7 days. ${ }^{30}$ In this study, the patients were divided into two sequential dosing cohorts. The first cohort of 20 neutropenic patients received posaconazole tablets $200 \mathrm{mg}$ QD, whereas the second dosing cohort of 34 patients received posaconazole tablets $300 \mathrm{mg}$ QD. Both cohorts received posaconazole tablets twice daily on day 1; thereafter, posaconazole tablet dosing was QD anytime during the day. Posaconazole tablets were taken without regard to food intake for a maximum of 28 days. The primary aim of this study was to determine whether a posaconazole dosage could achieve a desired steady-state $\mathrm{C}_{\text {avg }}$ plasma concentration range of 500-2,500 $\mathrm{ng} / \mathrm{mL}$. The exposure target was reached (day 8) in 15 of 19 (79\%) pharmacokineticevaluable patients who took $200 \mathrm{mg}$ posaconazole QD and in 31 of $32(97 \%)$ patients who took $300 \mathrm{mg}$ posaconazole QD. Overall, $300 \mathrm{mg}$ posaconazole QD achieved the desired exposure target. Therefore, the second part of this study predominantly focused on Phase III results and included neutropenic patients with AML or MDS, and post-allogeneic HSCT patients. The subjects received (without regard to food) posaconazole $300 \mathrm{mg}$ QD (after day 1, a twice-daily dose) for 28 days. The pharmacokinetic parameter of interest was the steady-state predicted average posaconazole concentration with lower and upper exposure target limits of $\geq 500$ and $<3,750 \mathrm{ng} / \mathrm{mL}$. A total of $210 \mathrm{AML}$, MDS, or HSCT subjects received and tolerated posaconazole tablets $300 \mathrm{mg}$ QD given as antifungal prophylaxis; 186 subjects were considered evaluable for pharmacokinetics. A strong correlation was found between the posaconazole trough concentration and observed $\mathrm{C}_{\text {avg }}$ values $\left(R^{2}=0.92\right)$. Only $1 / 186$ $(<1 \%)$ pharmacokinetic-evaluable subjects did not achieve the lower exposure target; 7/186 (4\%) subjects exceeded the upper exposure target. In this trial, a quartile analysis revealed no evidence of an increase in adverse event reporting with higher posaconazole exposure. This study revealed that posaconazole tablets $300 \mathrm{mg}$ QD had an acceptable safety profile similar to that previously reported for posaconazole oral suspension, and the most commonly reported treatmentrelated adverse events were nausea (11\%) and diarrhea $(8 \%) .{ }^{31}$ The advantages of the newly developed posaconazole tablet form are not affected by gastric acid suppression treatment in contrast to oral posaconazole suspension, which was demonstrated by Kraft et al. ${ }^{32}$ They investigated the effects of concomitant medications that alter gastric $\mathrm{pH}$ levels (antacids, ranitidine, and esomeprazole) and gastric motility (metoclopramide) on the pharmacokinetics of the new posaconazole tablets. This trial was a prospective, open-labeled, five-way crossover study in 20 healthy volunteers. For each treatment period, a single 400-mg dose (four 100-mg tablets) of posaconazole was given alone or with $20 \mathrm{~mL}$ of antacid ( $2 \mathrm{~g}$ of aluminum hydroxide and $2 \mathrm{~g}$ of magnesium hydroxide), ranitidine (150 mg), esomeprazole (40 mg), or metoclopramide $(15 \mathrm{mg})$. They reported that the mean $\mathrm{AUC}_{0-\infty}$ values for the posaconazole tablet alone, posaconazole plus antacid, posaconazole plus ranitidine, posaconazole plus esomeprazole, and posaconazole plus metoclopramide were 42,406 (h.ng/mL), 42,468 (h·ng/mL), 39,287 (h·ng/mL), $41,574(\mathrm{~h} \cdot \mathrm{ng} / \mathrm{mL})$, and $38,513(\mathrm{~h} \cdot \mathrm{ng} / \mathrm{mL})$, respectively. Similarly, they found that the maximum concentration geometric mean ratios for posaconazole plus treatment compared with that for posaconazole alone were 1.06 for the antacid, 1.04 for ranitidine, 1.05 for esomeprazole, and 0.86 for metoclopramide. This study demonstrated that the pharmacokinetics of posaconazole tablets were similar when the drug was administered alone or with an antacid, ranitidine, esomeprazole, or metoclopramide. ${ }^{32}$ 


\section{Adverse effects}

The common treatment-related adverse reactions to oral posaconazole suspension include diarrhea, nausea, fever, vomiting, headache, coughing, and hypokalemia. ${ }^{18}$ Previous studies that investigated the pharmacokinetics and safety of the posaconazole tablet formulation revealed that the most commonly observed adverse effects were a mild increase in hepatic enzymes, diarrhea, headache, flatulence, and somnolence, which indicates that the treatment-related adverse effects of the posaconazole tablet form are similar to those of the posaconazole oral suspension. ${ }^{29-32}$

\section{Drug interactions}

Posaconazole undergoes hepatic metabolism by UDPglucuronidation, is a substrate for the membrane transporter P-glycoprotein, and an inhibitor of the CYP3A4 enzyme; therefore, posaconazole has various drug-drug interactions. ${ }^{11,12,18}$ Rifabutin, phenytoin, efavirenz, cimetidine, esomeprazole, digoxin, fosamprenavir, metoclopramide, ritonavir, atazanavir, tacrolimus, cyclosporine, sirolimus, midazolam, simvastatin, and other drugs that are metabolized by CYP3A4 are well-known drugs that interact with posaconazole. In contrast to posaconazole suspension, posaconazole tablets do not have clinically significant drug-drug interactions with esomeprazole and metoclopramide, and no dosage adjustments are required. ${ }^{11,12,18}$

\section{Posaconazole (oral suspension) prophylaxis for IFIs}

The prophylactic use of posaconazole oral suspension has been approved for invasive Aspergillus and Candida infections in patients 13 years of age and older who are at a high risk of developing these infections due to being severely immunocompromised, such as HSCT recipients with GVHD or patients with hematologic malignancies with prolonged neutropenia from chemotherapy. Moreover, posaconazole oral suspension has been approved for the treatment of oropharyngeal candidiasis similar to itraconazole and fluconazole. ${ }^{33}$

One of the largest clinical trials to investigate the prophylactic use of posaconazole in patients with neutropenia resulting from chemotherapy for AML or MDS was performed by Cornely et al. In this randomized, multicenter study, patients (13 years of age or older) received prophylaxis with each cycle of chemotherapy until recovery from neutropenia and complete remission, the occurrence of an IFI, or up to 12 weeks. A total of 304 patients were randomly assigned to receive posaconazole, and 298 patients were randomly assigned to receive fluconazole $(n=240)$ or itraconazole $(n=58)$. Proven or probable IFIs were reported in seven patients $(2 \%)$ in the posaconazole group, and in 25 patients $(8 \%)$ in the fluconazole and itraconazole groups $(P<0.001)$; therefore, these statistical criteria support the superiority of posaconazole. Moreover, significantly fewer patients in the posaconazole group had invasive aspergillosis (two or $1 \%$ versus 20 or $7 \%, P<0.001$ ). Additionally, survival was significantly longer among the recipients of posaconazole than among the recipients of fluconazole or itraconazole $(P=0.04)$. This study demonstrated that in patients who were undergoing chemotherapy for AML or MDS, posaconazole prevented IFIs more effectively than fluconazole or itraconazole and improved overall survival. ${ }^{34}$ In another large clinical study, Ulmann et al investigated posaconazole prophylaxis in an international, randomized, double-blinded trial of patients (13 years of age or older) with GVHD who were receiving immunosuppressive therapy. A total of 600 patients were enrolled. Of these patients, 301 received posaconazole and 299 received fluconazole. The incidences of IFIs were 5.3\% in the posaconazole group and $9.0 \%$ in the fluconazole group $(P=0.07)$. The incidence of proven or probable invasive aspergillosis was $2.3 \%$ in the posaconazole group versus $7.0 \%$ in the fluconazole group ( $P=0.006)$. Compared with the fluconazole group, fewer breakthrough IFIs were reported in the posaconazole group $(2.4 \%$ versus $7.6 \%, P=0.004)$, particularly invasive aspergillosis $(1.0 \%$ versus $5.9 \%, P=0.001)$. Moreover, the overall mortality was similar between the two groups; however, the number of deaths from IFIs was lower in the posaconazole group than in the fluconazole group $(1 \%$ versus $4 \% ; P=0.046)$. This study found that posaconazole was similar to fluconazole for prophylaxis against fungal infections among patients with GVHD. However, posaconazole was superior in preventing invasive aspergillosis and in reducing the rate of deaths related to fungal infections. ${ }^{35}$

In addition to these large randomized studies, many studies have investigated the efficacy of posaconazole prophylaxis in immunocompromised patients. The findings from these observational studies and single-center experiences in reallife settings support the use of posaconazole prophylaxis beyond clinical studies (Table 1). ${ }^{34,35}$ Posaconazole oral suspension has become the drug of choice for IFI prevention in AML or MDS patients with chemotherapy-induced neutropenia and in allogeneic HSCT recipients with GVHD. The Infectious Diseases Working Group of the German Society for Hematology and Oncology strongly recommends posaconazole prophylaxis in these patient populations as a standard of care with an A1 strength. ${ }^{36}$ 


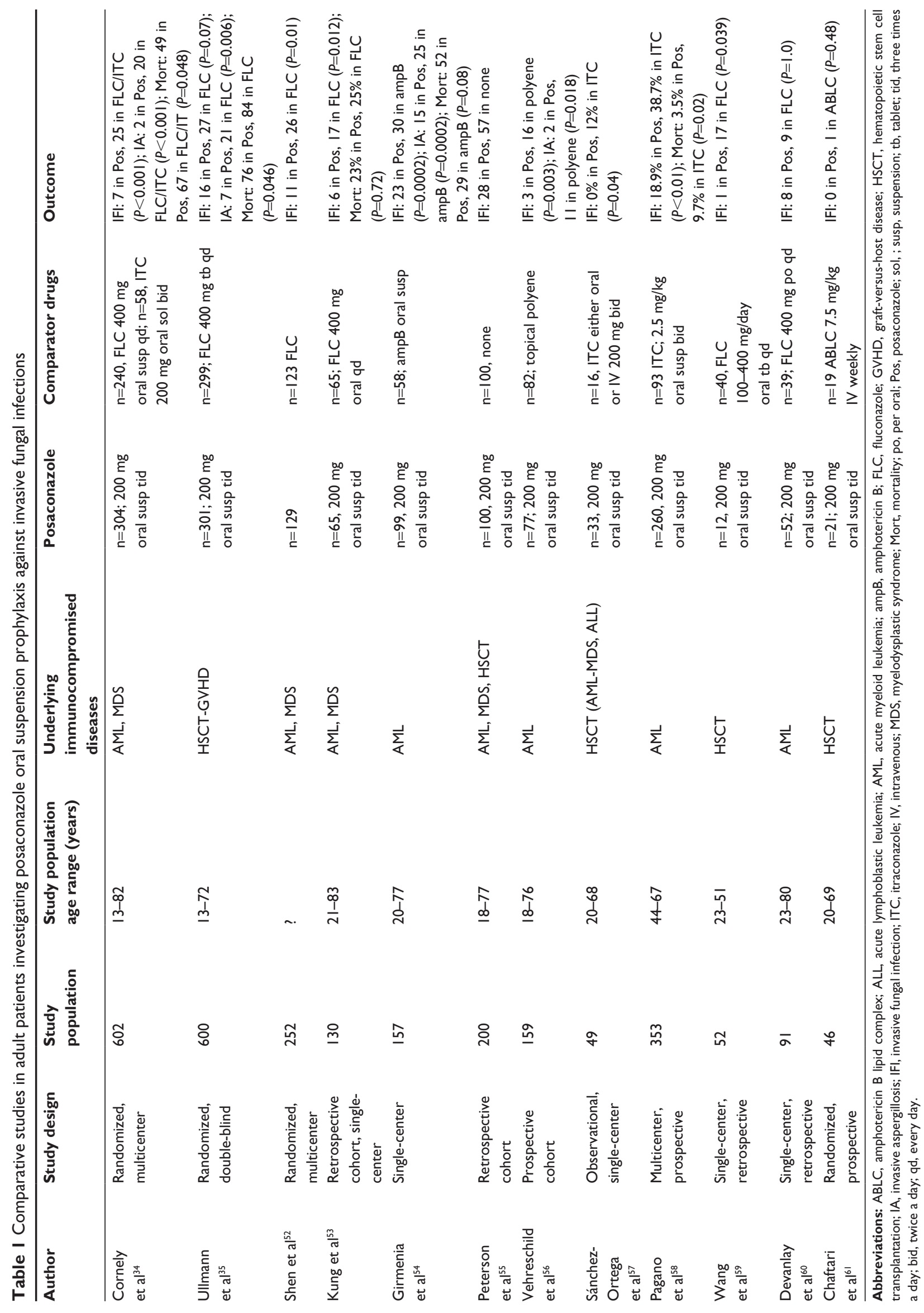


Limited data are available on the prophylactic use of posaconazole oral suspension in immunocompromised children, especially under 13 years of age. Döring et al retrospectively analyzed antifungal prophylaxis with posaconazole versus fluconazole or itraconazole in a singlecenter nonrandomized survey of 93 pediatric patients with neutropenia. Overall, 31 of 93 patients received fluconazole $5 \mathrm{mg} / \mathrm{kg} /$ day, 32 patients received itraconazole $5 \mathrm{mg} / \mathrm{kg}$ twice daily, and 31 patients received posaconazole $4 \mathrm{mg} /$ $\mathrm{kg}$ three times daily. Overall, two IFIs occurred in the fluconazole group, three IFIs occurred in the itraconazole group, and one IFI occurred in the posaconazole group. The blood analysis of liver and kidney parameters revealed a significant increase beyond the upper normal limit of alanine trasaminase (ALT) levels between the baseline and maximum values in all three groups. An increase in ALT levels that is 1.5 times greater from baseline and 2.5 times greater from the maximum value occurred in a total of 12 pediatric patients in the fluconazole group, eleven pediatric patients in the itraconazole group, and eight pediatric patients in the posaconazole group. An increase in aspartate aminotransferase (AST) levels that is 1.5 times greater from baseline and 2.5 times greater from the maximum value occurred in a total of seven pediatric patients in the fluconazole group, five pediatric patients in the itraconazole group, and six pediatric patients in the posaconazole group. This study demonstrated that posaconazole, fluconazole, and itraconazole are comparably effective in preventing IFIs in pediatric patients. ${ }^{37}$ In another study, Döring et al retrospectively assessed the safety, feasibility, and efficacy of prophylactic posaconazole in children who underwent allogeneic HSCT. Among 60 pediatric patients, 28 received posaconazole oral suspension $5 \mathrm{mg} / \mathrm{kg}$ twice daily, and 32 received posaconazole oral suspension $4 \mathrm{mg} / \mathrm{kg}$ three times daily. No IFIs were observed during treatment with posaconazole as antifungal prophylaxis, and five patients $(8.3 \%)$ died of causes other than IFIs during the study period. Only minor side effects potentially related to posaconazole were recorded in five $(8.3 \%)$ of the 60 patients, which included one patient with pruritus $(1.7 \%)$, three patients with nausea $(5 \%)$, and one patient with vomiting $(1.7 \%)$. This study found that posaconazole is a welltolerated, safe, and effective oral antifungal prophylaxis in pediatric patients who underwent high-dose chemotherapy and $\mathrm{HSCT}^{38}$ Moreover, Döring et al compared itraconazole, voriconazole, and posaconazole as oral antifungal prophylaxis in pediatric patients following allogeneic HSCT. Fifty consecutive pediatric patients received itraconazole
$(2 \times 5 \mathrm{mg} / \mathrm{kg} 7$ day), 50 received voriconazole $(2 \times 100 \mathrm{mg}$ day for body weight $<40 \mathrm{~kg}$ and $2 \times 200 \mathrm{mg}$ day for body weight $>40 \mathrm{~kg})$, and 50 received posaconazole $(3 \times 4 \mathrm{mg} / \mathrm{kg}$ day). No proven or probable IFIs were observed during the itraconazole, voriconazole, and posaconazole treatments. A total of five possible IFIs occurred: two in the itraconazole group (4\%) and three in the voriconazole group (6\%). Overall, nine of $150(6 \%)$ pediatric patients died of causes other than IFIs during the observation period: five in the itraconazole group, two in the voriconazole group, and two in the posaconazole group. Adverse events potentially related to the antifungal prophylaxis were observed in six patients $(12.0 \%)$ in the itraconazole group, seven (14.0\%) patients in the voriconazole group, and four ( $8.0 \%)$ patients in the posaconazole group. The findings of this study support previous findings that itraconazole, voriconazole, and posaconazole had a comparable efficacy as antifungal prophylaxis in pediatric patients after allogeneic HSCT. ${ }^{39}$ Yunus et al analyzed the safety and efficacy of azole-based, mold-active antifungal prophylaxis in children with AML and RALs. In this study, the patients with AML and RALs who were $\geq 13$ years of age received $200 \mathrm{mg}$ of posaconazole three times daily and patients $2-12$ years of age received $200 \mathrm{mg}$ of voriconazole two times daily from the completion of chemotherapy until hematopoietic recovery. The researchers enrolled a total of 40 patients during the 5-year observation period, of whom 36 received a total of 149 courses of chemotherapy. Azole prophylaxis was given in $87.2 \%$ of the episodes. No proven or probable IFIs were reported during the study. ${ }^{40}$ These studies demonstrated that posaconazole prophylaxis in children in an immunosuppressive state is effective and safe for the prevention of IFIs (Table 2).

\section{Cost-effectiveness of posaconazole in the prevention of IFIs}

Posaconazole is more effective in the prevention of IFIs than fluconazole or itraconazole (standard azoles) in immunocompromised patients, including patients with AML, MDS, and HSCT-GVHD; however, the economic burden of this preventive measure is important. Posaconazole prophylaxis is expected to be cost-effective compared with standard azole (fluconazole or itraconazole) prophylaxis. O'Sullivan et al investigated the cost-effectiveness of posaconazole oral suspension versus fluconazole or itraconazole in the prevention of IFIs among patients with AML or MDS and chemotherapy-induced neutropenia in the United States. They revealed that posaconazole was associated with 
Table 2 Clinical trials in pediatric patients investigating posaconazole oral suspension prophylaxis against invasive fungal infections

\begin{tabular}{|c|c|c|c|c|c|c|c|}
\hline Author & Study design & $\begin{array}{l}\text { Study } \\
\text { population } \\
\text { n }\end{array}$ & $\begin{array}{l}\text { Study } \\
\text { population } \\
\text { age range }\end{array}$ & $\begin{array}{l}\text { Underlying } \\
\text { immunocompromised } \\
\text { state }\end{array}$ & Pos group & Comparator drugs & Outcome \\
\hline $\begin{array}{l}\text { Döring } \\
\text { et } \mathrm{al}^{37}\end{array}$ & $\begin{array}{l}\text { Retrospective, } \\
\text { single-center }\end{array}$ & 93 & $\begin{array}{l}9 \text { months to } \\
17.7 \text { years }\end{array}$ & $\begin{array}{l}\text { AML, ALL, MDS, NHL, } \\
\text { solid tumors }\end{array}$ & $\mathrm{n}=30 ; 4 \mathrm{mg} / \mathrm{kg}$ tid & $\begin{array}{l}\mathrm{n}=32 ; \text { FLC } 5 \text { mg/kg/ } \\
\text { day; ITC } 5 \mathrm{mg} / \mathrm{kg} \text { bid }\end{array}$ & $\begin{array}{l}\text { IFI: I in } \\
\text { Pos, } 5 \text { in } \\
\text { FLC/ITC }\end{array}$ \\
\hline $\begin{array}{l}\text { Döring } \\
\text { et a }{ }^{38}\end{array}$ & $\begin{array}{l}\text { Retrospective, } \\
\text { single-center }\end{array}$ & 60 & $<12$ years & HSCT & $\begin{array}{l}\mathrm{n}=60 ; 5 \mathrm{mg} / \mathrm{kg} \\
\text { bid, } 4 \mathrm{mg} / \mathrm{kg} \text { tid }\end{array}$ & None & No IFI \\
\hline $\begin{array}{l}\text { Döring } \\
\text { et al }{ }^{39}\end{array}$ & $\begin{array}{l}\text { Retrospective, } \\
\text { single-center }\end{array}$ & 150 & $0.6-17.7$ years & HSCT & $\mathrm{n}=50 ; 4 \mathrm{mg} / \mathrm{kg}$ tid & $\begin{array}{l}\mathrm{n}=50 ; \text { ITC } 5 \mathrm{mg} / \mathrm{kg} \text { bid, } \\
\mathrm{n}=50 \text {; Vor } 2 \times 100 \mathrm{mg} \\
(\mathrm{BW}<40 \mathrm{~kg})\end{array}$ & $\begin{array}{l}\text { IFI: } 2 \text { in ITC, } \\
3 \text { in Vor }\end{array}$ \\
\hline $\begin{array}{l}\text { Yunus } \\
\text { et al }{ }^{40}\end{array}$ & $\begin{array}{l}\text { Observational, } \\
\text { single-center }\end{array}$ & 36 & $\begin{array}{l}10 \text { months to } \\
17 \text { years }\end{array}$ & $\begin{array}{l}\text { AML, recurrent } \\
\text { leukemias }\end{array}$ & $200 \mathrm{mg}$ tid & $\begin{array}{l}\text { Vor } 2 \times 200 \mathrm{mg} / \text { day } \\
(B W>40 \mathrm{~kg})\end{array}$ & No IFI \\
\hline
\end{tabular}

Abbreviations: ALL, acute lymphoblastic leukemia; AML, acute myeloid leukemia; bid, twice daily; BW, body weight; FLC, fluconazole; HSCT, hematopoietic stem cell transplantation; IFI, invasive fungal infection; ITC, itraconazole; MDS, myelodysplastic syndrome; NHL, non-hodgkin lymphoma; Pos, posaconazole; tid, twice daily; Vor, voriconazole.

fewer IFIs per patient ( 0.05 versus 0.11$)$ over 100 days of follow-up, lower discounted costs $(\$ 3,900$ versus $\$ 4,500)$, and increased life-years (2.50 versus 2.43 discounted) over a lifetime compared with fluconazole and itraconazole. Additionally, they found that posaconazole was cost-saving versus fluconazole or itraconazole. ${ }^{41}$ Tahami Monfared et al evaluated the economic cost of posaconazole versus standard (fluconazole or itraconazole) prophylaxis against IFIs in patients with prolonged neutropenia in Canada. ${ }^{42}$ They found that posaconazole was associated with fewer cases of IFIs ( 0.05 versus $0.11 ; P=0.003)$, increased lifeyears ( 2.52 years versus 2.43 years), and slightly lower costs $(\$ 6,601$ versus $\$ 7,045)$ per patient compared with standard azole therapy over a lifetime. Moreover, studies from European countries, including France, Italy, Switzerland, the Netherlands, Sweden, Greece, and Spain, demonstrated that posaconazole prophylaxis was more cost-effective and, in several studies, more cost-saving than standard azole prophylaxis in the prevention of IFIs in patients with AML, MDS, and HSCT-GVHD even with cancer. ${ }^{43-49}$ In addition to the clinical safety and efficacy trials, these economic analyses strongly suggest that posaconazole prophylaxis is superior to standard azole prophylaxis and more cost-effective and/or cost-saving in the prevention of IFIs in immunocompromised patients.

\section{Posaconazole (delayed-release tablet) prophylaxis for IFIs}

No published clinical trials are available on the use of posaconazole delayed-release tablets in the prevention of IFIs in immunocompromised patients. However, Conant et al reported on a 65-year-old man with recurrent Aspergillus brain abscesses who was previously treated with surgical resection and voriconazole for 1 year, and who was subsequently treated with posaconazole delayed-release tablets with a maintenance dose of $300 \mathrm{mg}$ per 24 hours, which resulted in a therapeutic serum concentration and was a safe and clinically effective treatment. This report was the first on the successful use of posaconazole tablets for the treatment of invasive aspergillosis. ${ }^{50}$ Before the accumulation of clinical data on the use of posaconazole delayed-release tablets in the prevention of IFIs in immunocompromised patients, an economic cost analysis of posaconazole tablets versus fluconazole or itraconazole in the prevention of invasive fungal disease among neutropenic patients in the United States was performed by Sung et al. ${ }^{51}$ They revealed that the average cost of antifungal prophylaxis was higher in the posaconazole tablet group compared with the fluconazole/ itraconazole group $(\$ 4,673$ versus $\$ 353)$. Additionally, they found that the costs that were associated with treating IFIs were lower in the posaconazole tablet group compared with the fluconazole/itraconazole group $(\$ 2,205$ versus $\$ 5,303)$. The incremental cost-effectiveness ratio for IFIs that were prevented by posaconazole was $\$ 18,898$ versus fluconazole/ itraconazole. In the current health care environment, the authors concluded that posaconazole tablets are a costeffective alternative to fluconazole or itraconazole in the prevention of IFIs among neutropenic patients with AML and MDS in the USA.

\section{Conclusion}

The newly developed posaconazole delayed-release tablet formulation enables patients in an immunosuppressive state to receive concomitant medication and food, which negatively affect the bioavailability of posaconazole oral suspension. Oral posaconazole formulation is superior to standard azoles 
(fluconazole or itraconazole) and more cost-effective in the prevention of IFIs in immunocompromised patients. To determine the clinical benefits of the posaconazole delayed-release tablet formulation either in the treatment or in the prevention of IFIs, well-designed clinical efficacy and safety studies are needed in both adult and pediatric populations.

\section{Disclosure}

The author report no conflicts of interest in this work.

\section{References}

1. Neofytos D, Lu K, Hatfield-Seung A, et al. Epidemiology, outcomes, and risk factors of invasive fungal infections in adult patients with acute myelogenous leukemia after induction chemotherapy. Diagn Microbiol Infect Dis. 2013;75:144-149.

2. Groll AH, Castagnola E, Cesaro S, et al. Fourth European Conference on Infections in Leukaemia (ECIL-4): guidelines for diagnosis, prevention, and treatment of invasive fungal diseases in paediatric patients with cancer or allogeneic haemopoietic stem-cell transplantation. Lancet Oncol. 2014;15:e327-e340.

3. Lanternier F, Cypowyj S, Picard C, et al. Primary immunodeficiencies underlying fungal infections. Curr Opin Pediatr. 2013;25:736-747.

4. Hachem R, Hanna H, Kontoyiannis D, Jiang Y, Raad I. The changing epidemiology of invasive candidiasis: Candida glabrata and Candida krusei as the leading causes of candidemia in hematologic malignancy. Cancer. 2008;112(11):2493-2499.

5. Pagano L, Caira M, Candoni A, et al. The epidemiology of fungal infections in patients with hematologic malignancies: the SEIFEM-2004 study. Haematologica. 2006;91:1068-1075.

6. Cho SY, Choi HY. Opportunistic fungal infection among cancer patients. A ten-year autopsy study. Am J Clin Pathol. 1979;72(4):617-621.

7. Goodman JL, Winston DJ, Greenfield RA, et al. A controlled trial of fluconazole to prevent fungal infections in patients undergoing bone marrow transplantation. $N$ Engl J Med. 1992;26;326(13):845-851.

8. Hof H. A new, broad-spectrum azole antifungal: posaconazole - mechanisms of action and resistance, spectrum of activity. Mycoses. 2006; 49 Suppl 1:2-6.

9. Munayyer HK, Mann PA, Chau AS, et al. Posaconazole is a potent inhibitor of sterol 14alpha-demethylation in yeasts and molds. Antimicrob Agents Chemother. 2004;48:3690-3696.

10. Kwon DS, Mylonakis E. Posaconazole: a new broad-spectrum antifungal agent. Expert Opin Pharmacother. 2007;8:1167-1178.

11. Guarascio AJ, Slain D. Review of the new delayed-release oral tablet and intravenous dosage forms of posaconazole. Pharmacotherapy. 2015;35:208-219.

12. McKeage K. Posaconazole: a review of the gastro-resistant tablet and intravenous solution in invasive fungal infections. Drugs. 2015;75(4): $397-406$.

13. Lass-Flörl C. Susceptibility testing in Aspergillus species complex. Clin Microbiol Infect. 2014;20 Suppl 6:49-53.

14. Castanheira M, Messer SA, Jones RN, Farrell DJ, Pfaller MA. Activity of echinocandins and triazoles against a contemporary (2012) worldwide collection of yeast and moulds collected from invasive infections. Int $J$ Antimicrob Agents. 2014;44:320-326.

15. Sabatelli F, Patel R, Mann PA, et al. In vitro activities of posaconazole, fluconazole, itraconazole, voriconazole, and amphotericin B against a large collection of clinically important molds and yeasts. Antimicrob Agents Chemother. 2006;50:2009-2015.

16. Sun QN, Fothergill AW, McCarthy DI, Rinaldi MG, Graybill JR. In vitro activities of posaconazole, itraconazole, voriconazole, amphotericin B, and fluconazole against 37 clinical isolates of zygomycetes. Antimicrob Agents Chemother. 2002;46:1581-1582.
17. Noxafil ${ }^{\circledR}$ (posaconazole) [package insert]. Whitehouse Station, NJ: Merck and Co, Inc.; 2014.

18. US Food and Drug Administration. Noxafil ${ }^{\circledR}$ (posaconazole) oral suspension. Product information. Silver Spring: US Food and Drug Administration. Available from: http://www.accessdata.fda.gov/drugsatfda_docs/ label/2009/022003s0071bl.pdf. Accessed March 21, 2015.

19. Krieter P, Flannery B, Musick T, Gohdes M, Martinho M, Courtney R. Disposition of posaconazole following single-dose oral administration in healthy subjects. Antimicrob Agents Chemother. 2004;48: 3543-3551.

20. Ghosal A, Hapangama N, Yuan Y, et al. Identification of human UDPglucuronosyltransferase enzyme(s) responsible fort the glucuronidation of posaconazole (Noxofil). Drug Metab Dispos. 2004;32:267-271.

21. Courtney R, Sansone A, Smith W, et al. Posaconazole pharmacokinetics, safety, and tolerability in subjects with varying degrees of chronic renal disease. J Clin Pharmacol. 2005;45:185-192.

22. Krishna G, Sansone-Parsons A, Martinho M, Kantesaria B, Pedicone L. Posaconazole plasma concentrations in juvenile patients with invasive fungal infection. Antimicrob Agents Chemother. 2007;51:812-818.

23. Courtney R, Pai S, Laughlin M, Lim J, Batra V. Pharmacokinetics, safety, and tolerability of oral posaconazole administered in single and multiple doses in healthy adults. Antimicrob Agents Chemother. 2003;47:2788-2795.

24. Gubbins PO, Krishna G, Sansone-Parsons A, et al. Pharmacokinetics and safety of oral posaconazole in neutropenic stem cell transplant recipients. Antimicrob Agents Chemother. 2006;50:1993-1999.

25. Gross BN, Ihorst G, Jung M, Wäsch R, Engelhardt M. Posaconazole therapeutic drug monitoring in the real-life setting: a single-center experience and review of the literature. Pharmacotherapy. 2013;33: $1117-1125$

26. Bryant AM, Slain D, Cumpston A, Craig M. A post-marketing evaluation of posaconazole plasma concentrations in neutropenic patients with hematologic malignancy receiving posaconazole prophylaxis. Int J Antimicrob Agents. 2011;37:266-269.

27. Courtney R, Radwanski E, Lim J, Laughlin M. Pharmacokinetics of posaconazole coadministered with antacid in fasting or nonfasting healthy men. Antimicrob Agents Chemother. 2004;48:804-808.

28. Krishna G, Ma L, Martinho M, O'Mara E. Single-dose phase I study to evaluate the pharmacokinetics of posaconazole in new tablet and capsule formulations relative to oral suspension. Antimicrob Agents Chemother. 2012;56:4196-4201.

29. Krishna G, Ma L, Martinho M, Preston RA, O’Mara E. A new solid oral tablet formulation of posaconazole: a randomized clinical trial to investigate rising single- and multiple-dose pharmacokinetics and safety in healthy volunteers. J Antimicrob Chemother. 2012;67:2725-2730.

30. Duarte RF, López-Jiménez J, Cornely OA, et al. Phase $1 \mathrm{~b}$ study of new posaconazole tablet for prevention of invasive fungal infections in high-risk patients with neutropenia. Antimicrob Agents Chemother. 2014;58:5758-5765.

31. Cornely OA, Duarte RF, Haider S, et al. Phase 3 Pharmacokinetics (PK) and Safety Study of Posaconazole (POS) Tablet in Patients at Risk for Invasive Fungal Infection. Abstract presented at: 23rd European congress of clinical microbiology and infectious diseases; April 28, 2013; Berlin.

32. Kraft WK, Chang PS, van Iersel ML, Waskin H, Krishna G, Kersemaekers WM. Posaconazole tablet pharmacokinetics: lack of effect of concomitant medications altering gastric $\mathrm{pH}$ and gastric motility in healthy subjects. Antimicrob Agents Chemother. 2014;58: 4020-4025.

33. US Food and Drug Administration. Highlights of Prescribing Information. Silver Spring: US Food and Drug Administration. Available from: http://www.accessdata.fda.gov/drugsatfda_docs/label/2010/0220 03s008,022027s001lbl.pdf. Accessed March 21, 2015.

34. Cornely OA, Maertens J, Winston DJ, et al. Posaconazole vs fluconazole or itraconazole prophylaxis in patients with neutropenia. N Engl J Med. 2007;356:348-359. 
35. Ullmann AJ, Lipton JH, Vesole DH, et al. Posaconazole or fluconazole for prophylaxis in severe graft-versus-host disease. $N \mathrm{Engl} \mathrm{J} \mathrm{Med.}$ 2007;356:335-347.

36. Tacke D, Buchheidt D, Karthaus M, et al. Primary prophylaxis of invasive fungal infections in patients with haematologic malignancies. 2014 update of the recommendations of the Infectious Diseases Working Party of the German Society for Haematology and Oncology. Ann Hematol. 2014;93:1449-1456.

37. Döring M, Eikemeier M, Cabanillas Stanchi KM, et al. Antifungal prophylaxis with posaconazole vs fluconazole or itraconazole in pediatric patients with neutropenia. Eur J Clin Microbiol Infect Dis. Epub February 14, 2015.

38. Döring M, Müller C, Johann PD, et al. Analysis of posaconazole as oral antifungal prophylaxis in pediatric patients under 12 years of age following allogeneic stem cell transplantation. BMC Infect Dis. 2012;12:263.

39. Döring M, Blume O, Haufe S, et al. Comparison of itraconazole, voriconazole, and posaconazole as oral antifungal prophylaxis in pediatric patients following allogeneic hematopoietic stem cell transplantation. Eur J Clin Microbiol Infect Dis. 2014;33:629-638.

40. Yunus S, Pieper S, Kolve H, Goletz G, Jürgens H, Groll AH. Azole-based chemoprophylaxis of invasive fungal infections in paediatric patients with acute leukaemia: an internal audit. J Antimicrob Chemother. 2014;69:815-820.

41. O’Sullivan AK, Pandya A, Papadopoulos G, et al. Cost-effectiveness of posaconazole versus fluconazole or itraconazole in the prevention of invasive fungal infections among neutropenic patients in the United States. Value Health. 2009;12:666-673.

42. Tahami Monfared AA, O'Sullivan AK, Rotstein C, Papadopoulos G. Economic evaluation of posaconazole versus standard azole therapy as prophylaxis against invasive fungal infections in patients with prolonged neutropenia in Canada. Can J Infect Dis Med Microbiol. 2012;23:59-64.

43. Athanasakis K, Petrakis I, Kyriopoulos J. Posaconazole vs fluconazole/ itraconazole in the prophylaxis of invasive fungal infections in immunocompromised patients: a cost-effectiveness analysis in Greece. J Med Econ. 2013;16:678-684.

44. Grau S, de la Cámara R, Sabater FJ, et al. Cost-effectiveness of posaconazole versus fluconazole or itraconazole in the prevention of invasive fungal infections among high-risk neutropenic patients in Spain. BMC Infect Dis. 2012;12:83.

45. Michallet M, Gangneux JP, Lafuma A, et al. Cost effectiveness of posaconazole in the prophylaxis of invasive fungal infections in acute leukaemia patients for the French healthcare system. J Med Econ. 2011;14:28-35.

46. Greiner RA, Meier Y, Papadopoulos G, O’Sullivan AK, Imhof A. Costeffectiveness of posaconazole compared with standard azole therapy for prevention of invasive fungal infections in patients at high risk in Switzerland. Oncology. 2010;78:172-180.

47. Jansen JP, O’Sullivan AK, Lugtenburg E, Span LF, Janssen JJ, Stam WB. Economic evaluation of posaconazole versus fluconazole prophylaxis in patients with graft-versus-host disease (GVHD) in the Netherlands. Ann Hematol. 2010;89:919-926.
48. Lundberg J, Höglund M, Björkholm M, Åkerborg Ö. Economic evaluation of posaconazole versus fluconazole or itraconazole in the prevention of invasive fungal infection in high-risk neutropenic patients in Sweden. Clin Drug Investig. 2014;34:483-489.

49. Lazzaro C. [Economic evaluation of posaconazole in prophylaxis of invasive fungal infections in Italian neutropenic patients with acute myeloid leukaemia or myelodysplastic syndrome]. Infez Med. 2010;18:91-103. Italian.

50. Conant MM, Sha BE, Proia LA. Use of posaconazole delayedrelease tablets for treatment of invasive aspergillosis. Mycoses. Epub February 27, 2015.

51. Sung AH, Marcella SW, Xie Y. An update to the cost-effectiveness of posaconazole vs fluconazole or itraconazole in the prevention of invasive fungal disease among neutropenic patients in the United States. J Med Econ. Epub March 2, 2015:1-8.

52. Shen Y, Huang XJ, Wang JX, et al. Posaconazole vs fluconazole as invasive fungal infection prophylaxis in China: a multicenter, randomized, open-label study. Int J Clin Pharmacol Ther. 2013;51:738-745.

53. Kung HC, Johnson MD, Drew RH, Saha-Chaudhuri P, Perfect JR. Clinical effectiveness of posaconazole versus fluconazole as antifungal prophylaxis in hematology-oncology patients: a retrospective cohort study. Cancer Med. 2014;3:667-673.

54. Girmenia C, Frustaci AM, Gentile G, et al. Posaconazole prophylaxis during front-line chemotherapy of acute myeloid leukemia: a singlecenter, real-life experience. Haematologica. 2012;97:560-567.

55. Peterson L, Ostermann J, Rieger H, Ostermann H, Rieger CT. Posaconazole prophylaxis - impact on incidence of invasive fungal disease and antifungal treatment in haematological patients. Mycoses. 2013;56:651-658.

56. Vehreschild JJ, Rüping MJ, Wisplinghoff $\mathrm{H}$, et al. Clinical effectiveness of posaconazole prophylaxis in patients with acute myelogenous leukaemia (AML): a 6 year experience of the Cologne AML cohort. J Antimicrob Chemother. 2010;65:1466-1471.

57. Sánchez-Ortega I, Patiño B, Arnan M, et al. Clinical efficacy and safety of primary antifungal prophylaxis with posaconazole vs itraconazole in allogeneic blood and marrow transplantation. Bone Marrow Transplant. 2011;46:733-739.

58. Pagano L, Caira M, Candoni A, et al. Evaluation of the practice of antifungal prophylaxis use in patients with newly diagnosed acute myeloid leukemia: results from the SEIFEM 2010-B registry. Clin Infect Dis. 2012;55:1515-1521.

59. Wang CH, Kan LP, Lin HA, et al. Clinical efficacy and safety of primary antifungal prophylaxis with posaconazole versus fluconazole in allogeneic blood hematopoietic stem cell transplantation recipients-A retrospective analysis of a single medical center in Taiwan. J Microbiol Immunol Infect. Epub October 13, 2014

60. Devanlay C, Tavernier-Tardy E, Bourmaud A, et al. Impact of Fluconazole versus Posaconazole Prophylaxis on the Incidence of Fungal Infections in Patients Receiving Induction Chemotherapy for Acute Myeloid Leukemia. Biomed J. Epub October 30, 2014.

61. Chaftari AM, Hachem RY, Ramos E, et al. Comparison of posaconazole versus weekly amphotericin B lipid complex for the prevention of invasive fungal infections in hematopoietic stem-cell transplantation. Transplantation. 2012;94:302-308.
Infection and Drug Resistance

\section{Publish your work in this journal}

Infection and Drug Resistance is an international, peer-reviewed openaccess journal that focuses on the optimal treatment of infection (bacterial, fungal and viral) and the development and institution of preventive strategies to minimize the development and spread of resistance. The journal is specifically concerned with the epidemiology of antibiotic

\section{Dovepress}

resistance and the mechanisms of resistance development and diffusion in both hospitals and the community. The manuscript management system is completely online and includes a very quick and fair peerreview system, which is all easy to use. Visit http://www.dovepress.com/ testimonials.php to read real quotes from published authors. 